\title{
AVALIAÇÃO E CLASSIFICAÇÃO DE PRAÇAS COM O USO DE VEÍCULOS ÁEREOS NÃO TRIPULADOS (VANT)
}

\author{
EVALUATION AND CLASSIFICATION OF SQUARES WITH THE USE OF \\ UNMANNED AERIAL VEHICLES (UAV)
}

Jozrael Henriques Rezende ${ }^{1}$, Leonardo Rodrigues Aroni², Valéria Lopes Rodrigues ${ }^{3}$

\begin{abstract}
RESUMO
Praças são espaços públicos não edificados muito acessíveis à população urbana. Seus benefícios ambientais, entretanto, dependem de suas características em relação à vegetação arbórea e à permeabilidade do solo. Esse trabalho avaliou seis praças localizadas na zona central de Jaú/SP. Foram realizados levantamentos a campo para medir as áreas permeáveis e impermeáveis. Para mensurar o índice de cobertura de copa foi utilizado um Veículo Aéreo Não Tripulado. As praças foram caracterizadas e classificadas considerando o grau de impermeabilização do solo, a existência de vegetação arbórea e o índice de cobertura de copa, para verificar quais delas podem ser consideradas componentes da floresta urbana, uma vez que todas apresentam vegetação arbórea. A somatória das áreas totaliza $47.482,00 \mathrm{~m}^{2}$. A maior praça tem $13.992,60 \mathrm{~m}^{2}$ e a menor $3.791,71 \mathrm{~m}^{2}$. O grau de impermeabilização do solo variou entre $39 \%$ e $82 \%$ e o índice de cobertura de copa entre $49 \%$ e $94 \%$. Os valores obtidos quanto ao grau de impermeabilização do solo e índice de cobertura de copa resultaram na classificação de todas as praças na tipologia "Praça-Arborização". O emprego do VANT mostrou-se adequado para a obtenção dos dados de cobertura de copa.
\end{abstract}

Palavras-chave: Cobertura de Copa; Impermeabilização do Solo; Vegetação Arbórea

\begin{abstract}
Squares are unbuilt public spaces that are very accessible to the urban population. Its environmental benefits, however, depend on its characteristics in relation to tree vegetation and soil permeability. The present study evaluated six squares located in the central zone of Jaú/SP. Field surveys were conducted to measure permeable and impermeable areas. In order to measure the canopy coverage index, an Unmanned Aerial Vehicle (UAV) was used. The squares were characterized and classified considering the degree of soil permeability, the existence of tree vegetation and the canopy coverage index, to verify which ones can be considered as components of the urban forest, since all of them present tree vegetation. The amount of the areas presents a total of $47,482.00 \mathrm{~m}^{2}$. The biggest square presents $13,992.60 \mathrm{~m}^{2}$ and the smallest one presents $3,791.71 \mathrm{~m}^{2}$. The degree of soil permeability varied between $39 \%$ and $82 \%$ and the canopy coverage index between $49 \%$ and $94 \%$. The values obtained related to the degree of soil permeability and the canopy coverage index allowed all the squares to be classified in the "SquareAfforestation" typology. The use of UAV demonstrated to be adequate to obtain canopy cover data.
\end{abstract}

Keywords: Canopy Coverage; Soil Waterproofing; Tree Vegetation.

\footnotetext{
Recebido em 24.03.2020 e aceito em 11.05.2020

1 Doutor em Ecologia e Recursos Naturais. Docente da Faculdade de Tecnologia de Jahu. Jaú/SP. Email: jozrael.rezende@fatec.sp.gov.br

2 Tecnólogo em Meio Ambiente e Recursos Hídricos. Faculdade de Tecnologia de Jahu. Jaú/SP. Email: leo.aroni@hotmail.com

3 Doutora em Geotecnia. Docente da Faculdade de Tecnologia de Jahu. Jaú/SP. Email: valeria.rodrigues3@fatec.sp.gov.br
} 


\section{INTRODUÇÃO}

O crescimento desordenado e as ocupações irregulares do solo, processos comuns à maioria das cidades brasileiras nas últimas décadas têm dificultado a integração das áreas construídas com as áreas verdes, provocando diminuição da qualidade de vida nas cidades. Um dos problemas decorrentes dessa questão está relacionado ao aumento das temperaturas nas áreas urbanas tanto em zonas residenciais quanto comerciais (BROWN et al., 2015).

As áreas verdes são definidas como espaços livres urbanos compostos por vegetação arbórea, arbustiva e rasteira, com solo livre de edificações ou coberturas impermeabilizantes, de acesso público ou não, e que exerçam as funções ecológicas, estéticas e de lazer (BARGOS; MATIAS, 2011). Quando públicas, essas áreas podem favorecer a permanência e o desenvolvimento de atividades sociais e, consequentemente, a vitalidade urbana (ROQUE; REZENDE, 2017).

A vegetação, em especial o componente arbóreo, possibilita microclimas urbanos diferenciados por meio do sombreamento, da proteção solar, da atenuação da variação das temperaturas urbanas e da retenção de umidade do solo e do ar. Além disso, contribui para a melhoria da paisagem e do conforto ambiental, diminuindo a poluição atmosférica, sonora e visual, servindo de abrigo à fauna, qualificando sítios urbanos e permitindo a identificação e o pertencimento com as comunidades (BASSO; CORRÊA, 2014; MARTINI; BIONDI; BATISTA, 2019).

A fim de intensificar os benefícios e evitar conflitos com outros equipamentos urbanos, a criação de áreas verdes, tais como os parques e as praças, bem como a arborização de vias públicas, deve ser integrada ao planejamento urbano, para levar benefícios indistintamente à todo o território urbano, gerando impactos positivos nos componentes ambientais (climáticos, hidrológicos e ecológicos), além dos sociais, econômicos, políticos e culturais (LIMA et al., 2020).

Segundo Souza, Cruz e Tucci (2012) quanto maior a área permeável na zona urbana, maior será o volume de água infiltrado no solo e, consequentemente, menor o escoamento superficial. Fica evidente o papel das áreas verdes, portanto, como estratégia para adaptar a urbanização ao ciclo hidrológico natural, adotando como princípio básico a permeabilidade máxima das águas de chuva nas bacias hidrográficas urbanas. No trabalho os autores destacam ainda a importância das árvores para interceptar, reter e evaporar água como dispositivo de controle das águas pluviais.

As árvores são importantes também para a melhoria do clima e atenuação da amplitude da variação da temperatura nas cidades. Martini et al.(2017) estudando os efeitos da floresta urbana e suas árvores no microclima de Curitiba concluíram que, independentemente da 
tipologia, elas exercem um papel fundamental na melhoria microclimáticas, em especial nas variáveis temperatura e umidade relativa do ar.

Especificamente no caso das praças, o grau de permeabilidade do solo e a existência de vegetação arbórea, que proporcione um determinado percentual de cobertura de copa, são fatores determinantes para promover benefícios ambientais. Essas características são determinantes para incluir as praças como integrantes da floresta urbana (VIEZZER, 2015).

Historicamente as praças são locais de convívio social, de reuniões, de congraçamentos, de encontros, onde as pessoas costumam se reunir para finalidades diversas, sejam comerciais, políticas, sociais ou religiosas, ou para desenvolverem atividades de entretenimento (ROBBA, MACEDO; 2010). As primeiras praças não desempenhavam o papel de área verde, porém, junto com o desenvolvimento das cidades, as praças ganharam novas formas e funções e, atualmente, muitas delas passaram a ter extrema importância para o conforto ambiental da população (BASSO; CORRÊA, 2014).

Para Biondi e Lima Neto (2012) a praça é uma das tipologias de áreas verdes mais acessíveis à população urbana, pois normalmente possuem equipamentos para atividades lúdicas e de lazer da população. Porém, para investigar os benefícios ambientais de uma praça, é necessário avaliar algumas de suas características no tocante a sua vegetação arbórea, entre elas o número de indivíduos e a diversidade de espécies (composição florística). Além desse inventário, é fundamental verificar outros dois atributos das praças: o grau de impermeabilização do solo e o índice de cobertura de copa (VIEZZER et al, 2018).

De Angelis, Castro e De Angelis Neto (2004) propõem uma metodologia para o estudo de praças no Brasil baseada em dois pontos fundamentais: estrutura física e uso. O primeiro é quantitativo e diz respeito ao levantamento, cadastramento, diagnóstico e avaliação dos equipamentos, da vegetação e da ocupação do solo. O segundo é qualitativo e diz respeito à opinião dos usuários.

A realização dos estudos de estrutura física pode ser facilitada com o uso de tecnologias de geoprocessamento e sensoriamento remoto para o mapeamento da cobertura vegetal e da identificação das áreas permeáveis e impermeáveis das praças. Gomes e Queiroz (2011), por exemplo utilizaram fotografias aéreas na escala de 1:10.000 e os softwares Global Mapper 7 e ArcGIS 9 para estimar o índice de cobertura vegetal com base na proporção entre área coberta com vegetação (copa das árvores) e superfície total da área, para quantificar a cobertura vegetal arbórea em Birigui/SP.

O uso de Veículos Aéreos Não Tripulados (VANT) como plataformas controláveis para aquisição de informação por via remota tem crescido, tornando possível obter informações geoespaciais detalhadas e de qualidade em tempo real com custos relativamente baixos. Os VANT têm sido utilizados na área florestal comercial com várias finalidades, inclusive a medição 
do grau de cobertura de copa, expresso por meio da percentagem da soma das áreas resultantes da projeção horizontal das copas em relação à área da parcela de inventário (SOARES et al., 2015). Esses equipamentos, entretanto, possuem limitações em áreas florestais ou de cobertura arbórea densa, pois a vegetação dificulta ou até inviabiliza a visualização na superfície do solo, dificultando o processamento de imagens em áreas sombreadas. Nesses casos o levantamento a campo pode ser necessário (HUNG et al.,2018).

Considerando que, na área central da cidade de Jaú/SP, as praças representam as únicas áreas verdes existentes, este estudo de propôs a avaliar seis praças localizadas nesta área, quanto ao grau de impermeabilização do solo, a existência da vegetação arbórea e o índice de cobertura de copa para verificar se elas geram benefícios ambientais, ou seja, cumprem seu papel ecológico. Para tanto foram utilizados levantamentos de campo e imagens geradas por VANT, para classificar as praças conforme a metodologia proposta por Viezzer (2015).

\section{MATERIAL E MÉTODOS}

O trabalho foi desenvolvido em Jaú - SP, localizado na região centro-oeste do Estado de São Paulo. Segundo o IBGE o município, cuja população estimada é de 146.338 mil habitantes, tem área de aproximadamente $687 \mathrm{~km}^{2}$ e sua zona urbana ocupa pouco mais de 30 $\mathrm{km}^{2}$ (Figura 1).

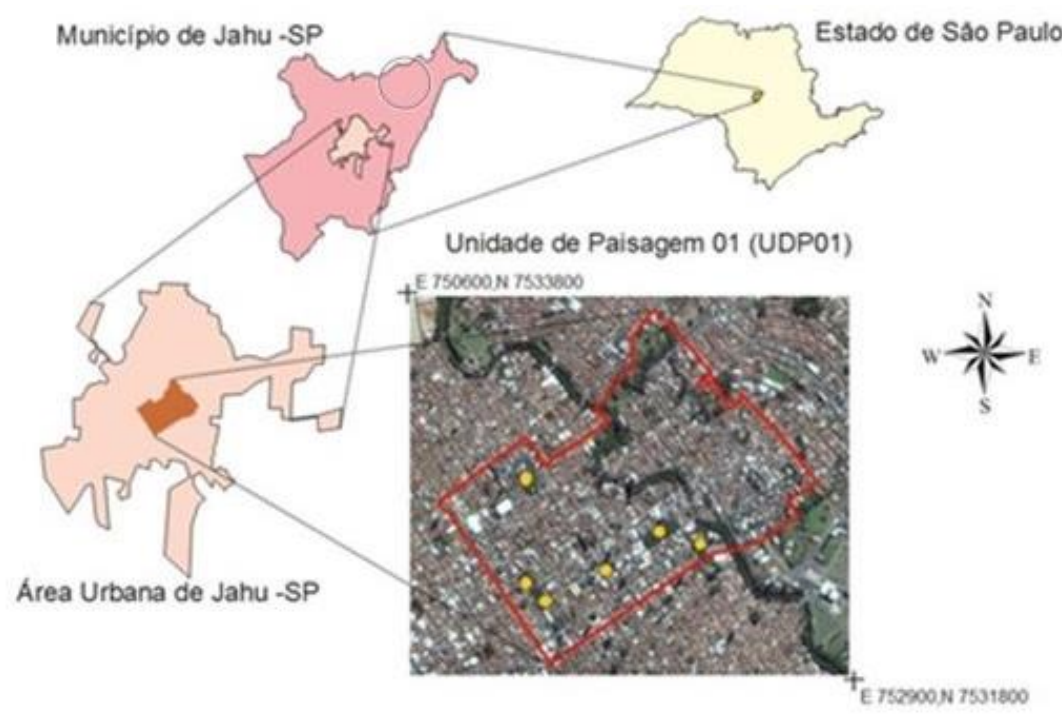

Figura 1. Localização das áreas de estudo, município de Jaú no estado de São Paulo evidenciando o perímetro da UDP ํㅡ. 01 com as seis praças

Figure 1. Location of the study areas, municipality of Jaú in the state of São Paulo showing the perimeter of UDP №. 01 with the six squares

A fisionomia de vegetação característica do município é a Floresta Estacional Semidecidual, além de uma área de transição entre floresta e cerrado (SMA, 2017). O clima no município de Jaú é do tipo "Aw", tropical chuvoso com inverno seco e mês mais frio com 
temperatura média superior a $18^{\circ} \mathrm{C}$. A precipitação média anual é de aproximadamente 1400 $\mathrm{mm}$, sendo o trimestre mais chuvoso de dezembro a fevereiro e período seco entre junho e agosto. O mês mais seco, agosto, tem precipitação média inferior a $30 \mathrm{~mm}$ (REZENDE; TECEDOR, 2017).

A Lei Complementar n‥ 443/2012, que dispõe sobre o zoneamento, o parcelamento, o uso e a ocupação do solo no município de Jaú, dividiu a zona urbana em sete regiões, denominadas Unidades da Paisagem (UDP). A UDP nํ01, corresponde a área central da cidade. Essa UDP tem área de $1.729 .621 \mathrm{~m}^{2}$. São 137 quarteirões e 20 praças, das quais seis foram escolhidas para o estudo. O critério de escolha considerou a data de criação e a localização das praças. Foram escolhidas as praças mais antigas do município, localizadas na área conhecida como centro histórico da cidade, inserido na UDP №. 01, na margem esquerda do Rio Jaú. As praças representam as únicas áreas verdes existentes nessa região da cidade. São elas: Praça Ettore Suriano (1), Praça da República (2), Praça Siqueira Campos (3), Praça Jorge Tibiriçá (4), Praça Osvaldo Galvão de França (5) e Praça Tancredo Neves (6) (Figura 2).

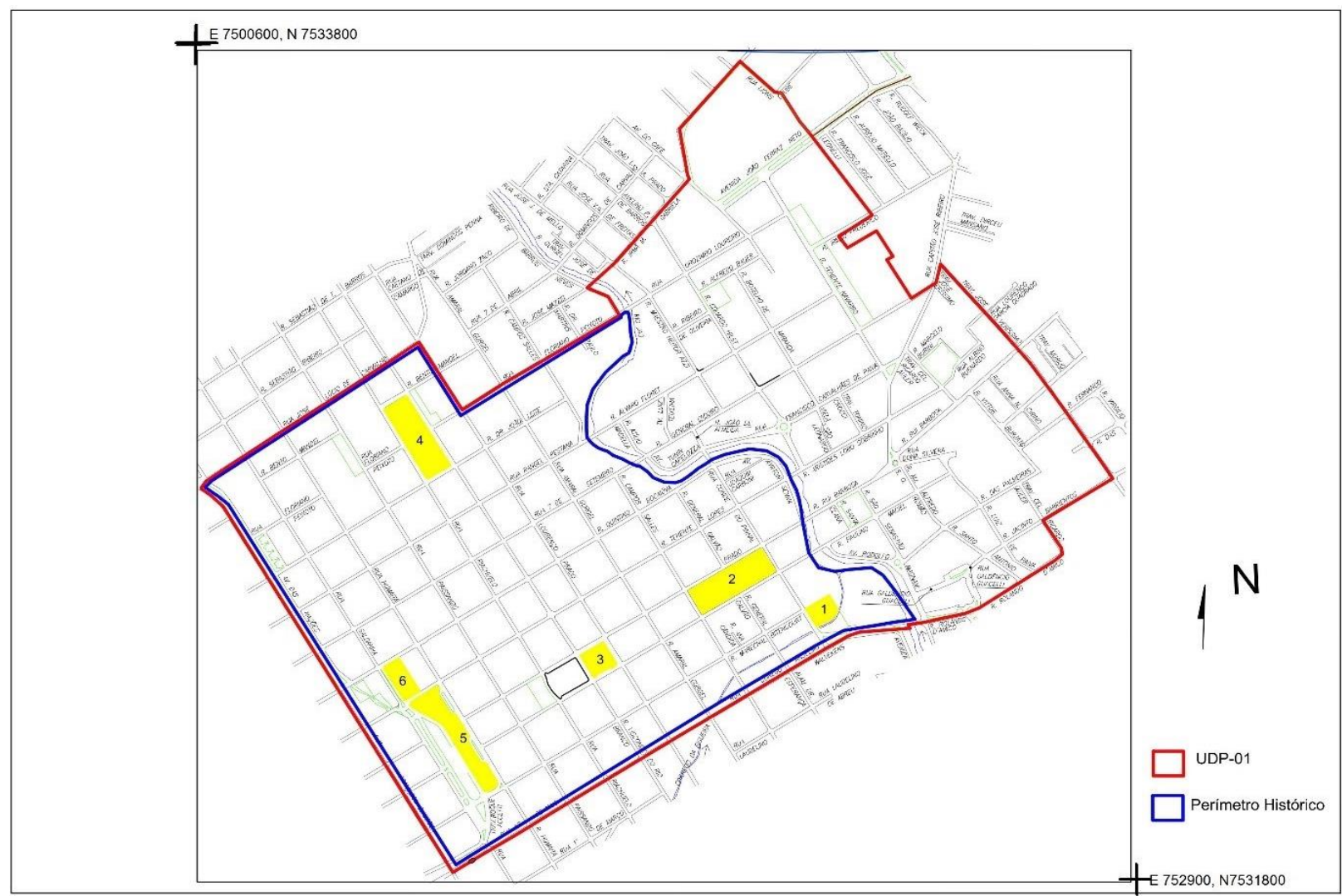

Figura 2. Áreas de estudo: seis praças incriadas na UDP 01 e perímetro histórico Figure 2 Study areas: six squares created at UDP 01 and historical perimeter

Para mensurar o grau de impermeabilização do solo, foram realizadas medições a campo com utilização de trena. Foram medidos todos os canteiros, bem como o perímetro de 
cada praça, gerando um croqui. Em seguida estes croquis foram transformados em desenhos no Software AutoCad 2018 para o cálculo das áreas. A somatória das áreas dos canteiros de cada praça foi considerada como área permeável. A área impermeável foi estimada subtraindo se a área permeável da área total.

Para a geração dos mapas das praças a partir do uso de VANT podem ser utilizados dois tipos de básicos de aeronaves: as de asa fixa (aviões e planadores) e as de asas rotativas (helicóptero e quad-rotors) (BRANDÃO, 2012). Optou-se por utilizar um VANT de asas rotativas. O equipamento utilizado foi um DJI modelo Maveric Pro, equipado com uma câmera de 12 megapixels. Ele está enquadrado na classe 3 e, por ter massa inferior a 250g, não precisa ser cadastrado ou registrado, independentemente do uso (ANAC, 2017).

O mapeamento foi obtido a partir de um plano de voo programado com a utilização de uma licença grátis temporária do software DroneDeploy. Esse aplicativo é compatível com os sistemas operacionais Android e IOS e possui integração com plataforma online. Foram realizados sobrevoos, com sobreposições planejadas, a 85 metros de altura das praças nos dias 10/03 e 05/05 de 2018. Assim como o plano e execução do voo, o conjunto de imagens também foi processado no software DroneDeploy, a fim de gerar um ortomosaico georreferenciado como produto principal do aerolevantamento. O ortomosaico georreferenciado foi a base para a fotointerpretação e estudos, sendo o processo de vetorização das feições de interesse realizada no software livre QGIS versão 2.18, para a estimativa do grau de cobertura de copa das árvores. As imagens obtidas nos sobrevoos foram comparadas com imagens disponíveis no Google Earth quanto a resolução.

Em seguida, as praças foram classificadas conforme a metodologia proposta por VIEZZER (2015), que estabelece seis tipologias, considerando o grau de impermeabilização do solo, a existência da vegetação arbórea e o índice de cobertura de copa (Tabela 1). Primeiramente verificou-se o grau de impermeabilização de cada praça e a seguir, como todas elas possuem vegetação arbórea, foi avaliado o índice de cobertura de copa, permitindo desta forma a classificação das praças na tipologia pertinente.

Tabela 1 Sistema de classificação das praças proposto por VIEZZER (2015)

Table 1. Classification system of squares proposed by VIEZZER (2015)

\begin{tabular}{|c|c|c|c|c|}
\hline Tipologia & $\begin{array}{c}\text { Grau de } \\
\text { Impermeabilização }\end{array}$ & $\begin{array}{l}\text { Vegetação } \\
\text { Arbórea }\end{array}$ & $\begin{array}{c}\text { Cobertura de } \\
\text { copa }\end{array}$ & $\begin{array}{l}\text { Componente da } \\
\text { Floresta Urbana }\end{array}$ \\
\hline Praça-Deserto & \multirow{3}{*}{$>30 \%$} & NÃO & $0 \%$ & NÃO \\
\hline Praça Jardim & & SIM & $<10 \%$ & NÁO \\
\hline Praça-Arborização & & SIM & $>10 \%$ & SIM \\
\hline Praça-Campo & \multirow{3}{*}{$<30 \%$} & NÃO & $0 \%$ & NÃO \\
\hline Praça-Cerrado & & SIM & $<10 \%$ & NÁO \\
\hline Praça-Floresta & & SIM & $>10 \%$ & SIM \\
\hline
\end{tabular}




\section{RESULTADOS E DISCUSSÃO}

A resolução das imagens geradas no sobrevoo realizado pelo VANT demonstra a superioridade em relação às imagens de satélite disponibilizadas pelo Google Earth (Figura 3). A melhor qualidade obtida nas imagens do VANT deve-se, principalmente, a menor altura do voo, e indica inúmeras possibilidades de utilização destes equipamentos no monitoramento e na avaliação das áreas verdes e da arborização urbana. Os ortomosaicos gerados e utilizados para a obtenção da área de cobertura de copa tem resolução média de $3,5 \mathrm{~cm} / \mathrm{px}$ (centímetro por pixel), ou seja, apresentam alto nível de resolução e detalhamento (Figura 4).

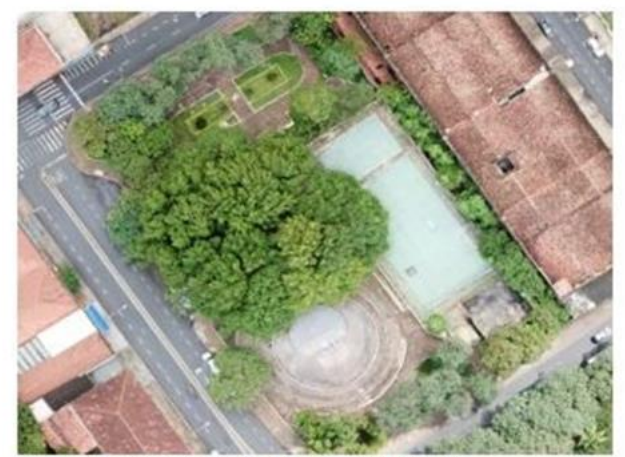

Praça Tancredo Neves - VANT (6)

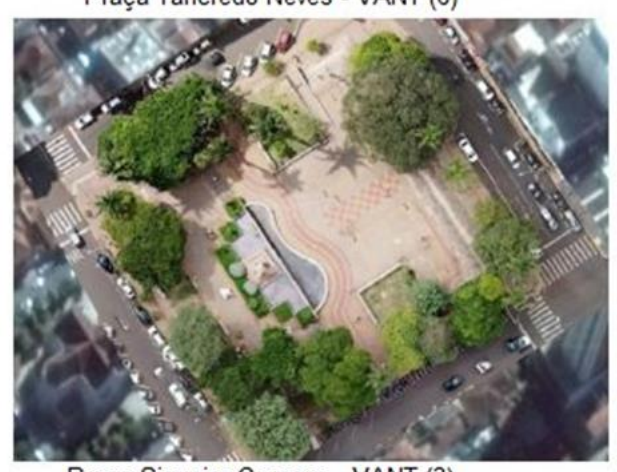

Praça Siqueira Campos - VANT (3)

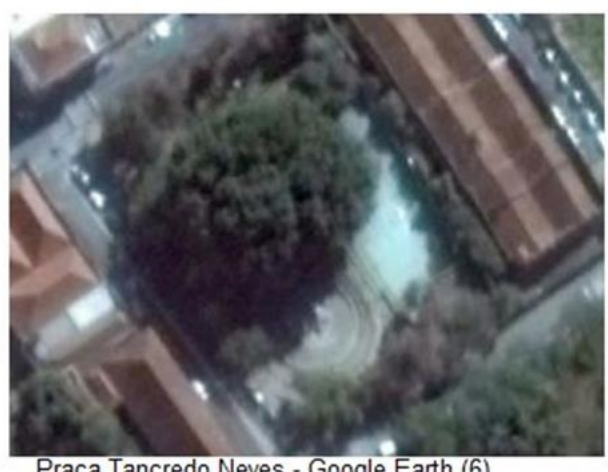

Praça Tancredo Neves - Google Earth (6)

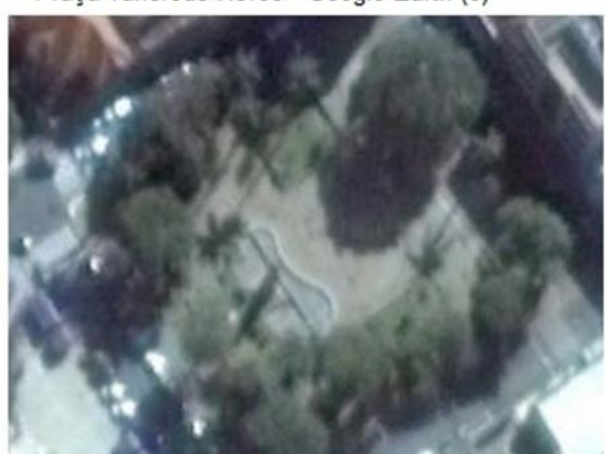

Praça Siqueira Campos - Google Earth (3)

Figura 3. Resolução das imagens geradas nos sobrevoos realizado pelo VANT comparada com a da imagem de satélite disponibilizada pelo Google Earth

Figure 3. Resolution of the images generated in the overflights carried out by the UAV compared to the satellite image provided by Google Earth

Os ortomosaicos processados pelo software DroneDeploy geraram imagens com qualidade suficiente para que fossem trabalhadas no QGis, permitindo a obtenção da área de cobertura de copa das praças com exatidão (Figura 5). A cobertura arbórea observada nas praças não permitiu a identificação das áreas dos canteiros, consideradas como áreas permeáveis no trabalho. Estas áreas foram estimadas no levantamento de campo conforme descrito. 


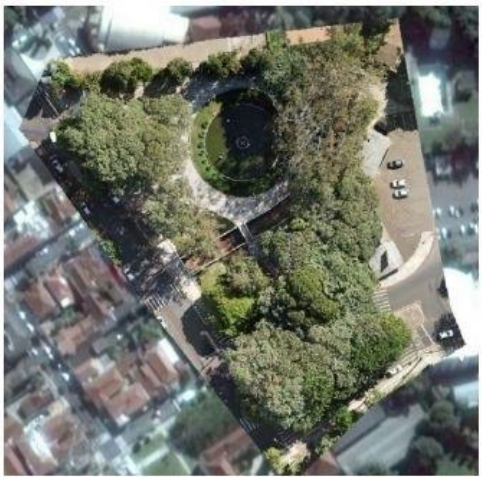

Praça Ettore Suriano

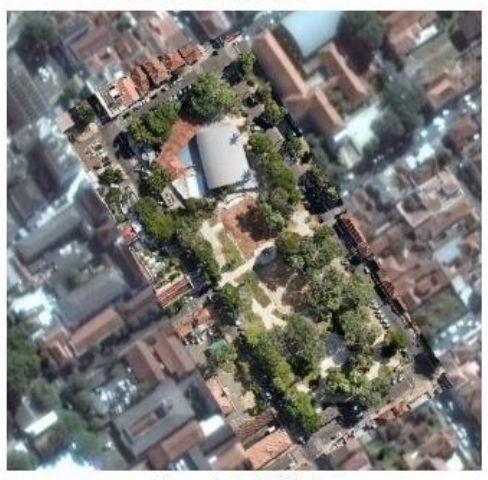

Praça Jorge Tibiriçá

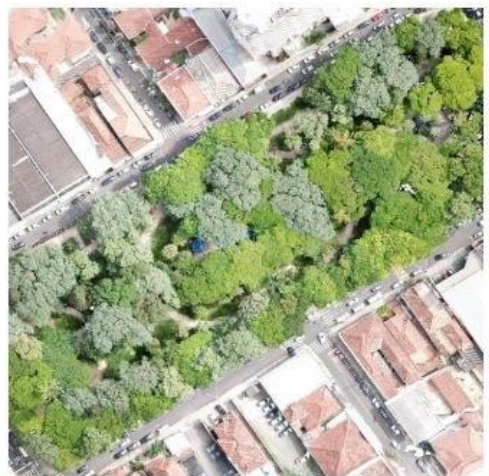

Praça da República

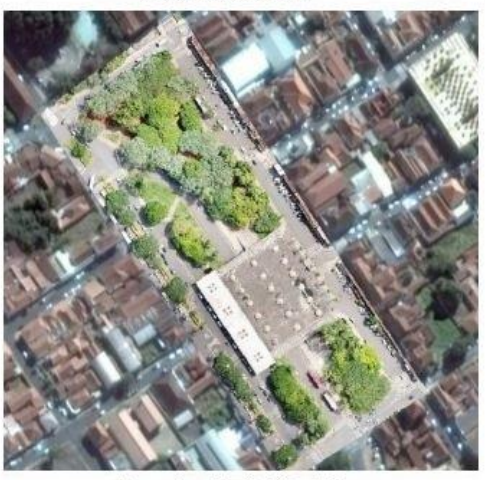

Praça Osvaldo Galvão de França

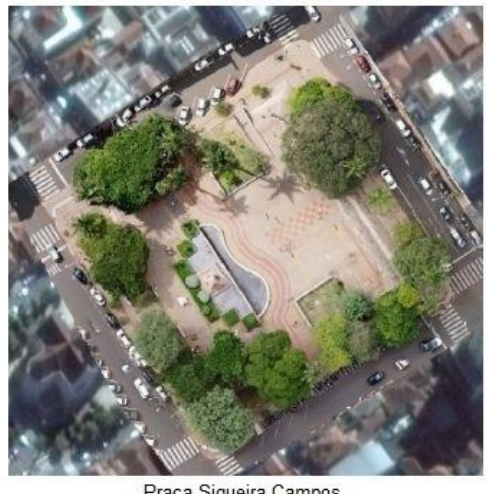

Praça Siqueira Campos

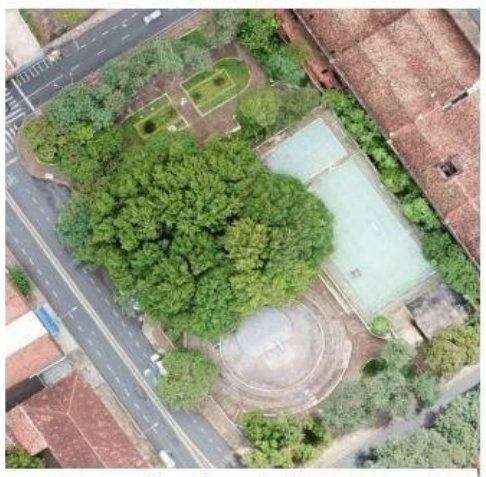

Praça Tancredo Neves

Figura 4. Ortomosaico das Praças gerado com média de $3,5 \mathrm{~cm} / \mathrm{px}$

Figure 4. Orthomosaic of the Squares generated with an average of $3.5 \mathrm{~cm} / \mathrm{px}$

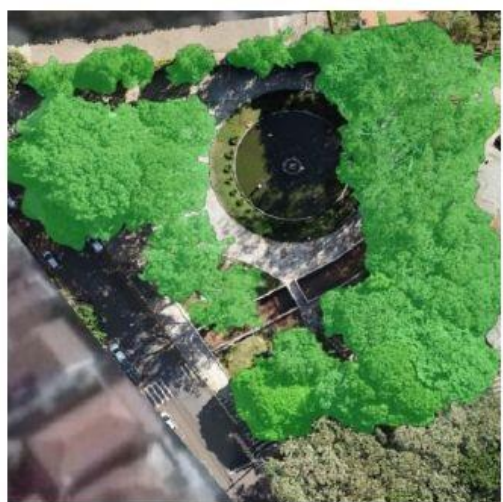

Praça Ettore Suriano (1)

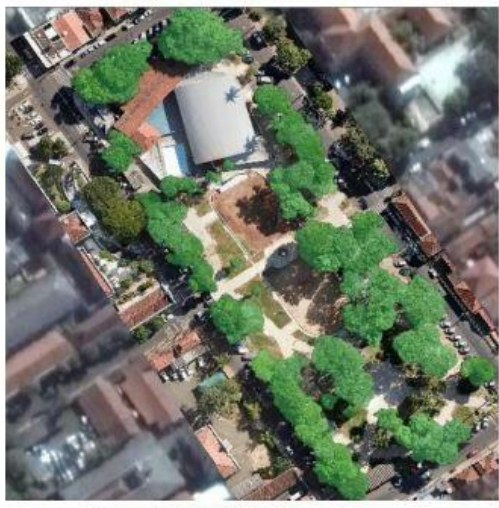

Praça Jorge Tibiriçá (4)

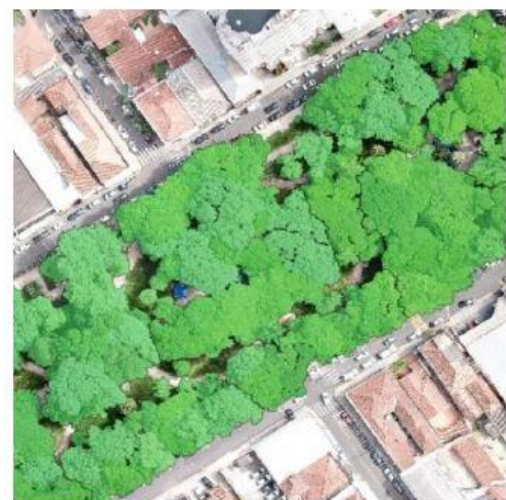

Praça da República (2)

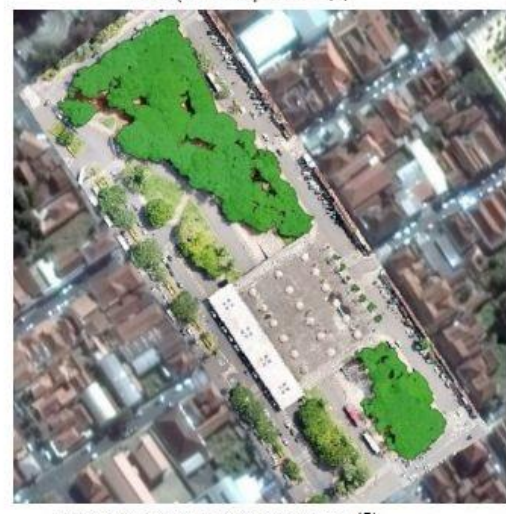

Praça Osvaldo Galvão de França (5)

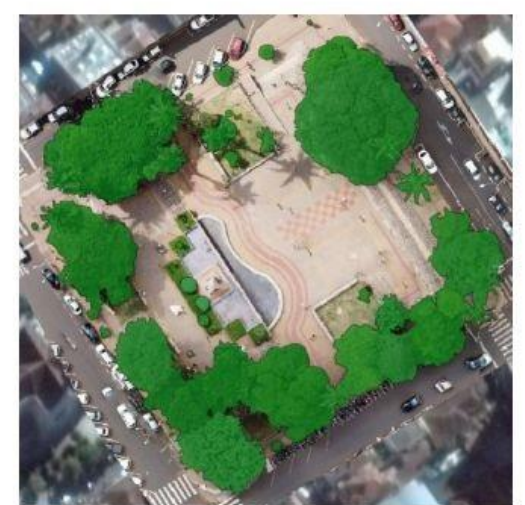

Praça Siqueira Campos (3)

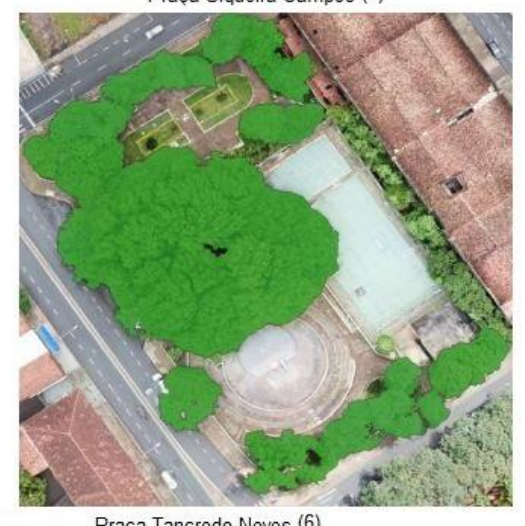

Praça Tancredo Neves (6)

Figura 5. Índice de cobertura de copa das praças - Jaú/SP

Figure 5. Index of canopy coverage of the squares - Jaú/SP 
As seis praças avaliadas neste estudo somam 47.482,00 $\mathrm{m}^{2}$ de área. A maior é a Praça da República (2), com 13.992,60 m², e a menor a Praça Ettore Suriano (1), com 3.791,71 m². A Praça da República (2) possui também a maior área de copa e a maior área permeável. A Praça Siqueira Campos (3) possui a menor área de cobertura de copa e a menor área permeável. A Praça Jorge Tibiriçá (4) apresenta a maior área impermeável (Tabela 2).

Tabela 2 Caracterização das Praças quanto à área total, cobertura de copa, áreas permeável e impermeável

Table 2. Characterization of the squares in terms of total area, canopy coverage, permeable and impermeable areas

\begin{tabular}{|c|c|c|c|c|c|c|c|}
\hline Praça & $\begin{array}{r}\text { Área Total } \\
\left(\mathrm{m}^{2}\right)\end{array}$ & $\begin{array}{r}\text { Cobertura } \\
\text { de Copa } \\
\left(\mathrm{m}^{2}\right)\end{array}$ & $\%$ & $\begin{array}{r}\text { Área } \\
\text { Permeável } \\
\left(\mathrm{m}^{2}\right)\end{array}$ & $\%$ & $\begin{array}{r}\text { Área } \\
\text { Impermeável } \\
\left(\mathrm{m}^{2}\right)\end{array}$ & $\%$ \\
\hline (1) Praça Ettore Suriano & 71 & $3.353,28$ & $88 \%$ & $1.216,70$ & $32 \%$ & $2.575,10$ & $68 \%$ \\
\hline (2) Praça da República & $13.992,60$ & $13.111,41$ & $94 \%$ & $8.595,65$ & $61 \%$ & $5.396,95$ & $39 \%$ \\
\hline (3) Praça Siqueira Campos & $4.300,92$ & $2.111,46$ & $49 \%$ & 786,20 & $18 \%$ & $3.514,72$ & $82 \%$ \\
\hline (4) Praça Jorge Tibiriçá & $11.700,86$ & $6.038,04$ & $52 \%$ & $5.324,83$ & $46 \%$ & $6.376,03$ & $54 \%$ \\
\hline (5) Praça Osvaldo Galvão de França & 10 &, 59 & $87 \%$ & $4.161,27$ & $48 \%$ & $4.585,83$ & $52 \%$ \\
\hline (6) Praça Tancredo Neves & 97 &, 39 & $91 \%$ & 818,00 & $17 \%$ & $4.112,97$ & $83 \%$ \\
\hline TOTAL & $47.482,00$ & $36.764,17$ & $77 \%$ & $20.902,7$ & $44 \%$ & $26.579,36$ & $56 \%$ \\
\hline
\end{tabular}

O grau de impermeabilização do solo variou entre $39 \%$ e $82 \%$, ou seja, nenhuma das praças avaliadas possui grau de impermeabilização inferior a $30 \%$. As áreas impermeáveis de todas as praças totalizaram $26.579,36 \mathrm{~m}^{2}, 56 \%$ da área. $\mathrm{O}$ índice de cobertura de copa das praças variou entre $49 \%$ e $94 \%$. A área de cobertura de copa das seis praças somou $36.764,17$ $\mathrm{m}^{2}$, o que representa $77 \%$ da área das praças cobertas pelas copas das árvores.

A Praça da República (2) apresentou o menor grau de impermeabilização e o maior índice de cobertura de copa e, 39\% e 94\% respectivamente. A Praça Tancredo Neves (6) e a Praça Siqueira Campos (3) apresentaram os maiores graus de impermeabilização, $83 \%$ e $82 \%$ respectivamente. A Praça Tancredo Neves (6) e a Praça Siqueira Campos (3), entretanto, apresentaram resultados distintos quanto ao índice de cobertura de copa, 91\% em (6) e 49\% em (3), o que demonstra que não existe, necessariamente, correlação entre o índice de cobertura de copa e o grau de impermeabilização do solo (Tabela 3).

Todas as praças foram classificadas como "Praça-Arborização" de acordo com a metodologia proposta por Viezzer (2015). São praças com graus de impermeabilização do solo variando de médio a alto, porém com presença de vegetação arbórea que proporciona elevados índices de cobertura de copa. Dessa forma todas as praças do estudo podem ser consideradas componentes da Floresta Urbana, pois possuem árvores e área de cobertura de copa superior a 10\%, conforme a definição de floresta pela Organização das Nações Unidas para Alimentação e Agricultura (FAO) e pela Convenção Quadro das Nações Unidas sobre Mudança do Clima (UNFCCC) (VIEZZER, 2015). 
Tabela 3 Percentual de cobertura de copa, grau de impermeabilização, classificação e enquadramento das Praças segundo Viezzer (2015)

Table 3. Percentage of canopy coverage, degree of waterproofing, classification and framing of Squares according to Viezzer (2015)

\begin{tabular}{lccccc}
\hline \multicolumn{1}{c}{ Praça } & $\begin{array}{c}\text { Grau de } \\
\text { Impermeabilização } \\
(\%)\end{array}$ & $\begin{array}{c}\text { Vegetação } \\
\text { Arbórea }\end{array}$ & $\begin{array}{c}\text { Cobertura } \\
\text { de Copa } \\
(\%)\end{array}$ & $\begin{array}{c}\text { Tipologia do } \\
\text { enquadramento }\end{array}$ & $\begin{array}{c}\text { Componente } \\
\text { da Floresta } \\
\text { Urbana }\end{array}$ \\
\hline (1) Praça Ettore Suriano & $68 \%$ & $\operatorname{sim}$ & $88 \%$ & $\begin{array}{c}\text { Praça- } \\
\text { Arborização }\end{array}$ & SIM \\
\hline (2) Praça da República & $39 \%$ & $\operatorname{sim}$ & $94 \%$ & $\begin{array}{c}\text { Praça- } \\
\text { Arborização }\end{array}$ & SIM \\
\hline (3) Praça Siqueira Campos & $82 \%$ & $\operatorname{sim}$ & $49 \%$ & $\begin{array}{c}\text { Praça- } \\
\text { Arborização }\end{array}$ & SIM \\
\hline (4) Praça Jorge Tibiriçá & $54 \%$ & $\operatorname{sim}$ & $52 \%$ & $\begin{array}{c}\text { Praça- } \\
\text { Arborização }\end{array}$ & SIM \\
\hline (5) Praça Osvaldo Galvão de França & $52 \%$ & $\operatorname{sim}$ & $87 \%$ & $\begin{array}{c}\text { Praça- } \\
\text { Arborização }\end{array}$ & SIM \\
\hline (6) Praça Tancredo Neves & $83 \%$ & $\operatorname{sim}$ & $91 \%$ & $\begin{array}{c}\text { Praça- } \\
\text { Arborização }\end{array}$ & SIM \\
\hline
\end{tabular}

Nucci (2001) observa, entretanto, que um espaço não edificado para ser identificado como área verde e desempenhar as principais funções socioambientais (estética, ecológica e lazer), deve ter predominantemente áreas plantadas, apresentando cobertura vegetal e solo permeável de, pelo menos, $70 \%$ de sua área total, o que significa que apenas $30 \%$ de sua área são passíveis de impermeabilização. No estudo de caso todas as praças apresentaram graus de impermeabilização superiores a esse valor. A Praça da República (2) foi a que teve um resultado mais próximo, 39\% de impermeabilização.

Viezzer (2014) estimou em 31,45\% a impermeabilização do solo em relação à área total de 157 praças em Curitiba/PR, mostrando que, em média, as praças amostradas apresentaram uma proporção de área impermeabilizada dentro do esperado para uma tipologia de área verde, muito embora tenha sido observada grande variação na proporção de área impermeabilizada entre elas. A média de impermeabilização do solo das praças desse estudo foi de $56 \%$. Esse número é um indicativo da necessidade de rever o grau de impermeabilização na implementação de novas praças na cidade visando intensificar os benefícios ambientais.

Em relação ao índice de cobertura de copa, segundo a metodologia, praças com mais de $10 \%$ de cobertura de copa são consideradas integrantes da floresta urbana. É de se esperar, entretanto, que quanto maior for o índice de cobertura de copa, maior será o sombreamento e consequentemente o conforto ambiental, que está diretamente associado a essa característica. Por isso é fundamental planejar adequadamente a arborização das praças quando da sua criação. Além disso é preciso adotar estratégias de manejo dessas áreas que permitam o livre e pleno desenvolvimento da vegetação arbórea, respeitando-se a arquitetura de copa natural das espécies para garantir os maiores índices de cobertura de copa (OLIVEIRA et al., 2019).

Praças com grande parte de suas árvores com copas degradadas por podas contínuas malfeitas podem deixar de cumprir suas funções ambientais plenamente, diminuindo os benefícios gerados, tendo em vista a importância das árvores para a melhoria do clima e 
atenuação da amplitude da variação da temperatura nas cidades (MARTINI et al., 2017) e para interceptar, reter e evaporar água como dispositivo de controle das águas pluviais (SOUZA; CRUZ; TUCCI, 2012). Além da diversidade de espécies, portanto, o estado geral das árvores é um dos aspectos da vegetação mais importantes relacionados à qualidade da arborização das praças. A caracterização das condições da arborização contribui para o conhecimento da qualidade do ativo florestal e para o diagnóstico das condições ambientais destes espaços favorecendo o manejo (DA SILVA et al., 2018).

Para propiciar o conforto nas praças, além de elevados percentuais de área permeável e de cobertura de copa, proporcionado bons índices de sombreamento é fundamental considerar suas características estéticas, responsáveis pelo conforto visual e a área de entorno. A existência de fatores causadores de poluição sonora e trânsito de veículos nas imediações podem comprometer o conforto acústico e a qualidade do ar. As perturbações causadas por esses agentes podem ser atenuadas em praças maiores (HIRASHIMA; ASSIS, 2017). Considerando o tamanho, as Praças da República (2) e Jorge Tibiriçá (3) são as que tem mais condições de atenuação desses fatores.

O software DroneDeploy oferece outras funções que podem ser importantes ferramentas na avaliação das praças e outras áreas verdes. $O$ aplicativo permite a geração de gráficos e mosaicos de elevação representando a distribuição dos objetos mais baixos e mais altos respectivamente, com isso é possível estimar a altura de indivíduos arbóreos. Quando existe e desnível no terreno da praça ou área verde, estas estimativas podem gerar alturas negativas. A função do software é importante para caracterizar o dossel. As tonalidades vermelhas indicam árvores acima de 15 metros de altura, os tons de amarelo de 10 a 15 metros, os tons em verde de 5 a 10 metros e os azuis abaixo de 5 metros de altura. É possível verificar a concentração de elementos por classes de altura dos componentes (Figura 6), bem como as alturas do dossel em cada praça (Figura 7). 

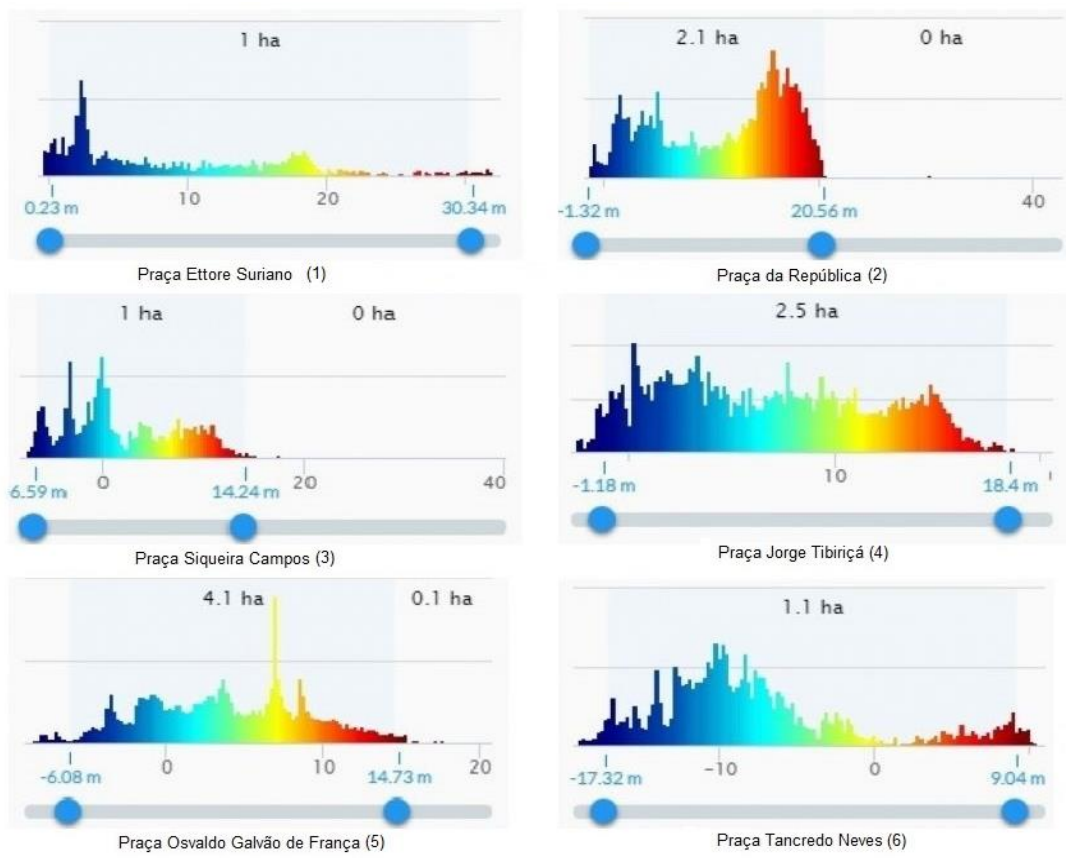

Figura 6. Gráficos de elevação de cada uma das praças

Figure 6. Elevation charts of each one of the squares

É possível observar, por exemplo, que a Praça da República (2) possui dossel quase contínuo acima dos 15 metros de altura. Também é possível verificar a ausência de cobertura arbórea em grande parte das Praças Ettore Suriano (1), Siqueira Campos (3), Jorge Tibiriçá (4) e Tancredo Neves (6) (Figura 7). As Praças (4) e (6) inclusive, foram as que apresentaram grau de impermeabilização do solo superiores a $80 \%$.

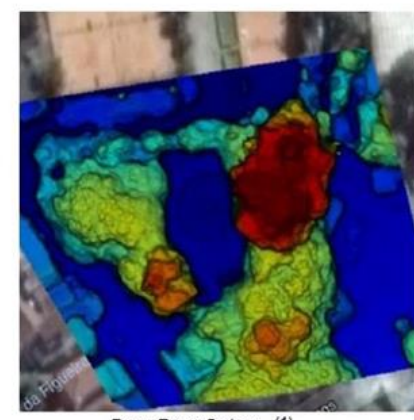

Praça Ettore Suriano (1)

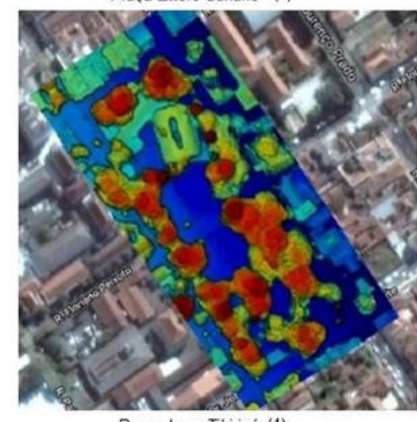

Praça Jorge Tibiriçá (4)

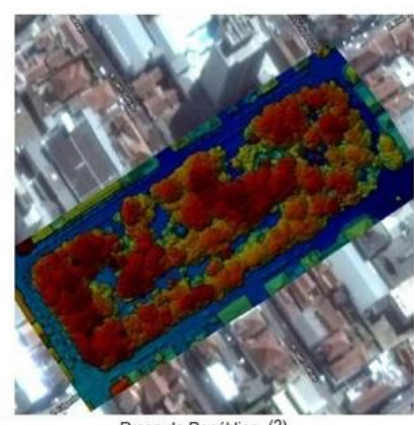

Praça da República (2)

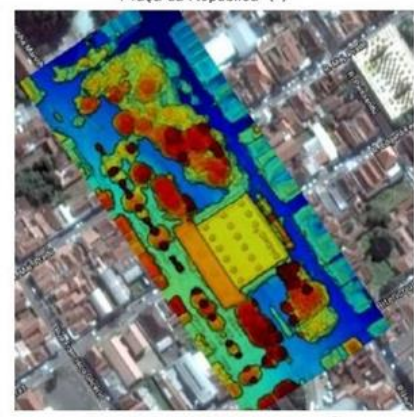

Praça Osvaldo Gavão de França (5)

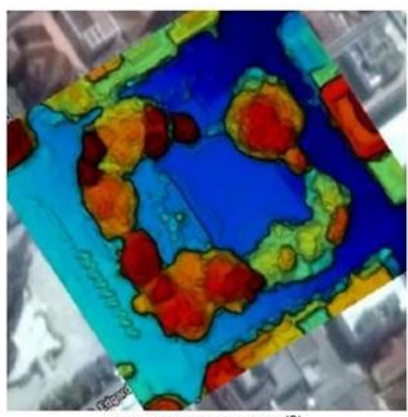

Praça Siqueira Campos (3)

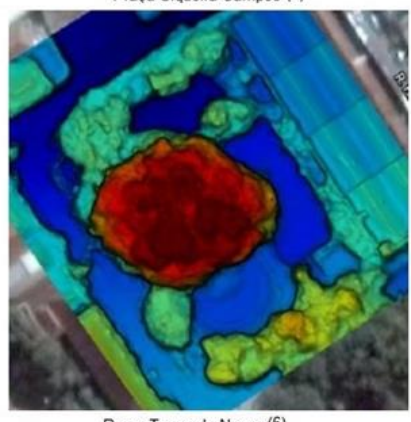

Praça Tancredo Neves (6)

Figura 7. Mosaicos de elevação gerados pelo aplicativo DroneDeploy

Figure 7. Elevation mosaics generated by the DroneDeploy app 
As praças podem desempenhar, além das funções sociais e estéticas, funções ambientais, ou seja, ecológicas, climatológicas e hidrológicas. Para tanto é fundamental a presença de indivíduos de espécies arbóreas, com diversidade de espécies e bom estado geral das árvores, que possam promover um elevado índice de cobertura de copa após o seu desenvolvimento, associado ao alto grau de permeabilidade do solo.

\section{CONCLUSÕES}

O emprego do Veículo Aéreo Não Tripulado mostrou-se adequado ao cálculo do índice de cobertura de copa das praças, além de permitir estimar a altura do dossel. Em relação a classificação das praças, baseada no grau de impermeabilização, na existência de vegetação arbórea e no índice de cobertura de copa; o enquadramento de todas as praças desse estudo na tipologia "Praça-Arborização" demonstram que elas são integrantes da floresta urbana e, portanto, desempenham funções ambientais importantes na região da cidade onde estão inseridas. O elevado grau de impermeabilização do solo das praças avaliadas demonstra a necessidade de alterar os requisitos de projetos de futuras praças da cidade no que diz respeito a essa característica, de maneira a propiciar áreas verdes com maiores percentuais de áreas permeáveis.

\section{REFERÊNCIAS}

AGÊNCIA NACIONAL DE AVIAÇÃO CIVIL - ANAC. Requisitos Gerais Para Aeronaves Não Tripuladas De Uso Civil (Regulamento Brasileiro Da Aviação Civil Especial - RBAC-E no 94), 2017. Disponível em: <https://www.anac.gov.br/assuntos/legislacao/legislacao-1/rbha-erbac/rbac/rbac-e-94>. Acesso em: 05 out. 2019

BARGOS, D. C.; MATIAS, L. F. Áreas verdes urbanas: um estudo de revisão e proposta conceitual. Revista da Sociedade Brasileira de Arborização Urbana. Piracicaba, v. 6, n. 3, p. 172-188, 2011.

BASSO, J. M.; CORRÊA, R. S. Arborização urbana e Qualificação da Paisagem. Paisagem e Ambiente: Ensaios, São Paulo, v.34, p. 129 - 148, 2014.

BIONDI, D.; LIMA NETO E. M. Distribuição espacial e toponímia das praças de Curitiba.

Revista da Sociedade Brasileira de Arborização Urbana. Piracicaba, v. 7, n. 3, p.31-43, 2012.

BRANDÃO, A. S.; PIZZETA, I .H. B.; CARELLI, R.; SARCINELLI-FILLHO, M. Modelagem e controle não linear subatuado de um quad-rotor: Parte 1. XIX Congresso Brasileiro de

Automática. Campina Grande, PB. 2012. p. 3102-3109. 
BROWN, R. D.; VANOS, J.; KENNY, N.; LENZHOLZER, S. Designing urban parks that ameliorate the effects of climate change. Landscape and Urban Planning, Amsterdã, v. 138, p. $118-131,2015$.

DA SILVA, A. D. P.; BATISTA, A. C.; GIONGO, M.; BIONDI, D. B; DOS SANTOS, A. F.; CACHOEIRA, J. N.; MACHADO, I. E. S. Aspectos qualitativos e quantitativos da arborização das praças públicas de Gurupi, TO, Brasil. Journal of Biotechnology and Biodiversity, PalmasTO, v.6. n.1, p. 209-216, 2018.

DE ANGELIS, B. L. D.; CASTRO, R. M.; DE ANGELIS NETO, G. Metodologia para levantamento, cadastramento, diagnóstico e avaliação de praças no Brasil. Engenharia Civil, Braga, v.4, n.1, p.57-70, 2004.

GOMES, M. F.; QUEIROZ D. R. E.; Avaliação da Cobertura Vegetal Arbórea na Cidade de Birigui com emprego de técnicas de geoprocessamento e sensoriamento remoto. Revista Geografar, Curitiba, v.6, n.2, p.93-117, 2011.

HIRASHIMA, S. Q. S.; ASSIS, E.S. conforto e eficiência energética no ambiente construído. Ambiente Construído, Porto Alegre, v.17, n.1, p. 7-22, 2018.

HUNG, M.N.W.B.; SAMPAIO, T.V.M.; SCHULTZ, G.B.; SIEFERT, C.A.C.; LANGE, D.R.; MARANGON, F.H.S.; SANTOS, I. Levantamento com Veículo Aéreo Não Tripulado para geração de Modelo Digital do Terreno em Bacia experimental com Vegetação Florestal esparsa. RA'EGA - O Espaço Geográfico em Análise, Curitiba, v. 43, p. 215 -231, 2018.

LIMA, G. V. B. A.; PEREIRA, M. M.; RIBEIRO JUNIOR, C. R.; DE AZEVEDO, L. E. C.; ARAÚJO, I. R. S. O direito à cidade arborizada: A arborização urbana como indicador da segregação socioeconômica em Belém do Pará. Revista da Sociedade Brasileira de Arborização Urbana, Curitiba, v.15, n.1, p. 79-96, 2020.

MARTINI, A.; BIONDI, D.; BATISTA, A. C. Tempo de conforto térmico proporcionado pela arborização de ruas. Acta Biológica Catarinense, Joinville, v. 6, n. 4, p. 5-14, 2019.

MARTINI, A.; BIONDI, D.; BATISTA, A. C.; SILVA FILHO, D. F. da. Análise Microclimática das diferentes tipologias de Floresta Urbana de Curitiba. Floresta, Curitiba, v. 47, n. 2, p. 137 - 144, 2017.

$\mathrm{NUCCl}$, J. C. Qualidade ambiental e adensamento urbano: um estudo de Ecologia e Planejamento da Paisagem aplicado ao distrito de Santa Cecília (MSP). São Paulo: Humanitas - FFLCH/USP, 2001. 235 p.

OLIVEIRA, J. D.; SCIPIONI, M. C.; DOS REIS, A. R. N.; XIMENES, E. Diagnóstico da arborização da Praça Centenário, Curitibanos, Santa Catarina, Brasil. Acta Biológica Catarinense, Joinville, v. 6, n. 3, p. 23-36, 2019.

REZENDE, J. H.; TECEDOR, N. aproveitamento de água de chuva de cobertura em edificações: dimensionamento do reservatório pelos métodos descritos na NBR 15527. Ambiente \& Água An Interdisciplinary Journal of Applied Science, Taubaté, v.12 n.6. p. 1040-1053, 2017. 
ROBBA, F.: MACEDO, S. S. Praças Brasileiras. $3^{\underline{a}}$ ed. São Paulo: Editora da Universidade de São Paulo. 2010. (Coleção Quapá)

ROQUE, L. C.; REZENDE, J. H. Influência da Arborização Urbana no Microclima. Estudo de Caso: Rua Voluntários da Pátria, Araraquara/SP. Revista de Tecnologia e Gestão da Fatec Jahu, Jaú, v. 10, n.1 p. 188-199, 2017.

SÃO PAULO (Estado). SECRETARIA DE ESTADO DO MEIO AMBIENTE - SMA. Resolução SMA no. 146, de 08 de novembro de 2017. Institui o Mapa de Biomas do Estado de São Paulo, e dá outras providências. 2017. Disponível em: <https://smastr16.blob.core.windows.net/ legislacao/2017/11/resolucao-sma-146-2017.pdf>. Acesso em: 19 ago. 2019

SOARES, P.; TOMÉ, M. CAMPAGNOLO, M; OLIVEIRA, J; OLIVEIRA, B; ARAÚJO, J; CÂMARA, F. A utilização de Veículos Aéreos Não Tripulados no inventário florestal - o caso do montado de sobro. VIII Conferência Nacional de Cartografia e Geodésia - Informação geoespacial para as gerações futuras: oportunidades e desafios. Ordem dos Engenheiros, Portugal, outubro 2015.

SOUZA, C. F.; CRUZ, M. A. S.; TUCCI, C. E. M. Desenvolvimento Urbano de Baixo Impacto: Planejamento e Tecnologias Verdes para a Sustentabilidade das Águas Urbanas. Revista Brasileira de Recursos Hídricos, Porto Alegre, v. 17, n. 2, p. 9-18, 2012.

VIEZZER, J. As linhas projetuais paisagísticas e a percepção dos usuários das praças de Curitiba-PR. Curitiba, 2014. 123 f. Dissertação (Mestrado em Engenharia Florestal), Universidade Federal do Paraná.

VIEZZER, J. A Floresta Urbana e o papel das Praças. In.: BIONDI, D. Floresta Urbana. Curitiba: O Autor, 2015. p.109-124.

VIEZZER, J.; BIONDI, D.; MARTINI, A.; GRISE, M. M. A Vegetação no Paisagismo das Praças de Curitiba/PR. Ciência Florestal, Santa Maria, v. 28, n. 1, p. 369-383, 2018. 